\title{
COLOBOMA LENTIS WITH ABNORMAL CILIARY BODY
}

BY

\section{T. HARRISON BUTLER}

BIRMINGHAM

THE following case is of interest, not only from its rarity, but because had its real nature not been recognized a harmless anomaly might have lead to the removal of a useful eye.

Mrs. D., aged 23 years, came to the Eye Department of the Coventry Hospital saying that she thought she needed glasses.

My house surgeon, Mr. Logan, examined her and found in the right eye what he thought might be a tumour in the ciliary region.

The following conditions were present:-

Externally the eye, which has a brown iris, is perfectly normal in aspect, without a trace of injection. The pupil is normal in size and reactions. The media are clear and the fundus normal. The vision of the right eye is $6 / 12$ that of the left, $6 / 4 \cdot 5$. There is no material error of refraction. The tension of each eye is normal.

Examination with $\mathrm{a}+20 \mathrm{D}$. lens behind the ophthalmoscope shows in the lower aspect of the vitreous chamber, and close behind the lens, a smooth grey circumscribed mass suggesting a sarcoma of the ciliary body.

Focal examination with the ordinary loupe by the light of a halfwatt 60 c.p. bulb reveals a brown mass, sponge-like in texture, with no trace of irregularity or of vascularization. In its centre but apparently unconnected with it, is a yellowish area. When the

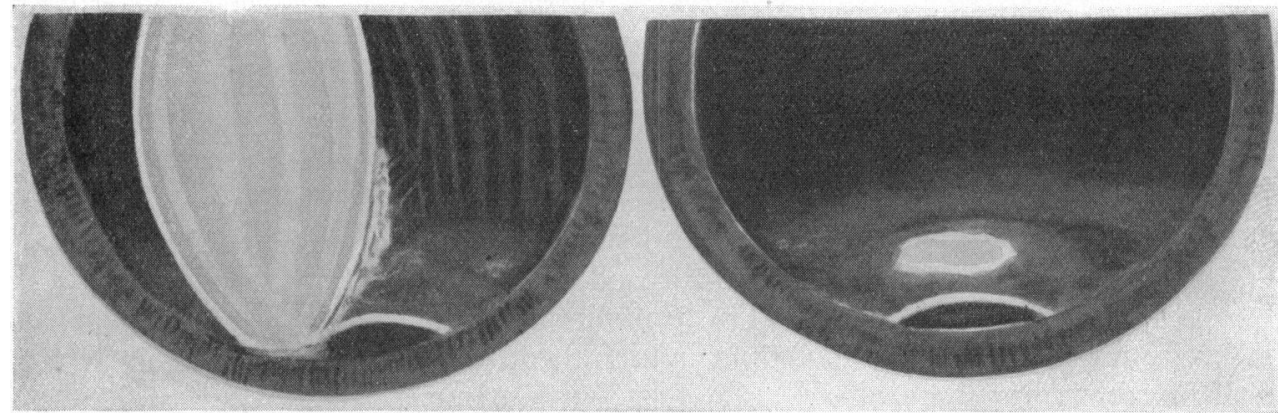

FIG. 1 .

The eye seen in optical section. The coloboma of the lens is clearly seen. The flocculent deposit is shown on the back of the lens. The brown mass occupies about one fifth of the circumference of the pupil.
FIG. 2.

The interior of the eye seen by focal illumination. The coloboma is seen below with its usual shining edge. The brown mass with the yellow area occupies the lower third of the picture. 
pupil was dilated a small coloboma of the lens was discovered. There appeared to be a small opacity in the lower part of the lens.

The slit-lamp examination with the broad beam showed that the mass had the texture and colour of ordinary uveal tissue, and that there was no vascularization. It merged with the ciliary body without any abrupt edge, and had no irregularity of surface that might be present in a new growth.

The vitreous was perfectly normal showing the usual films without any trace of infiltration with cells or larger particles.

When examined with the narrow beam in optical section, it was seen that the white area seen by focal illumination on the surface of the mass was really a flocculent filamentous deposit on the back of the lens. It extended downwards and was lost in the region of the coloboma.

The lens itself, except in the colobomatous area was perfectly clear, and showed the usual sutures and zones of discontinuity.

I came to the conclusion that the mass was due to an abnormal development of the ciliary body in the lower sector of the eye, probably a fusion of several processes, and that there could be no question of sarcomatous growth. Apart from the fact that the lens was obviously implicated in the abnormal picture, the absence of vascularization, the normal aspect of the vitreous, and the normal tension as estimated with the Schiötz tonometer, were evidence against tumour formation.

Mrs. D. has now been under observation for six months and no change has taken place in the eye.

\title{
CONSERVATION OF EYEDROPS
}

\author{
BY \\ DR. KLEIN MiKLós \\ FROM THE DEPARTMENT OF OPHTHALMOLOGY, \\ UNIVERSITY PÉCS, HUNGARY, PROFESSOR DR. K. ALBRICH
}

THE sterility of eyedrops is very important because they are used after operations which open the globe and also after perforating. injuries, when it is possible for micro-organisms to be carried with the drops into the internal part of the bulb, and thus cause dangerous infections.

First, we had to examine whether the eyedrops are infected or not. It is well known that most eyedrops, chiefly the alkaloids, become after more or less time opalescent, and, in these there 